\title{
The Human Inter Vertebral Disc - A Histological Approach
}

\author{
Article by Anuradha $\mathrm{K}^{1}$, Sujatha Kiran $\mathrm{P}^{2}$ \\ ${ }^{1}$ Department of Anatomy, Maheshwara Medical College, Patancheru, Telangana, India \\ ${ }^{2}$ Professor, Kamineni Institute of Medical Sciences, Narketpally, Nalgonda, India \\ E-mail: dkanuradha2003@gmail.com ${ }^{1}$
}

\begin{abstract}
The human intervertebral disc (IVD) is a very complex joint structure that can be made up of highly organized matrix laid down by relatively few cells in a specific manner. Macroscopically it can be separated in to three distinct components. The central gelatinous nucleus pulposus is contained within the more collagenous anulus fibrosus laterally and the cartilage end plates inferiorly and superiorly. The anulus consists of concentric rings or lamellae, with fibers in the outer lamellae continuing into the longitudinal ligaments and vertebral bodies. This arrangement allows the discs to facilitate movement and flexibility within what would be an otherwise rigid spine. With increasing age, the disc-particularly the nucleus-becomes less gelatinous and more fibrous, and cracks and fissures eventually form. More blood vessels begin to grow into the disc from the outer areas of the annulus. There is an increase in cell proliferation and formation of cell clusters as well as an increase in cell death. In the present study the microscopic anatomy of intervertebral disc of full term human foetus was examined the alignment of collagen Fibers \& distribution of chondrocytes in the annulus is observed with the help of Haematoxylin \& Eosin stain and Vangieson's stain. The Haematoxylin \& Eosin study reveals that the collagen fibers are arranged circularly \& the nucleus pulposus is of mucoid material, which is made up of degenerated notochordal cells.
\end{abstract}

Keywords: Inter vertebral disc, Anulus fibrosus, Nucleus pulposus, Histology.

\section{Introduction}

The Inter vertebral discs are a fibro cartilage type and provide strong attachments between the vertebral bodies, uniting them into a continuous semi rigid column and forming the inferior half of the anterior border of the inter vertebral foramen. In aggregate, the discs account for $25 \%$ of the length (height) of the vertebral column, as well as permitting movement between adjacent vertebrae, their resilient deformability allows them to serve as shock absorbers (1).

Mesenchymal cells between cephalic and caudal parts of the original sclerotome segment do not proliferate but fill the space between two precartilaginous vertebral bodies and forms the intervertebral disc. Notochord contributes the nucleus pulposus, which is later surrounded by circular fibers of the anulus fibrosus. Combined, these two structures form the intervertebral disc (2).

The human intervertebral disc (IVD) is a very complex joint structure that can be separated macroscopically into at least three distinct components: 1) the nucleus pulposus (NP) representing a centrally located gelatinous homogenous mass and of mucoid material with a few multinucleated notochordal cells 2) the anulus fibrosus (AF) consisting of concentrically organized layers of collagen fibrils 3) the cartilaginous endplates (EP), which separate the nucleus pulposus and anulus fibrosus from the adjacent vertebral bone. Any disturbance of the integrity and interplay of one of the three structures can result in a compromised function of the intervertebral disc (3)

According to Buckwalter JA et al like no other musculoskeletal tissue, the lumbar intervertebral disc undergoes very extensive destructive changes with age and degeneration (4). The degree of this tissue destruction is closely linked to age, but different components of the disc undergo more extensive alterations than others (5).

The present study focuses on the extent of cellularity, structural changes of granular matrix degeneration, the formation of clefts and tears and mucoid matrix changes in the nucleus pulposus and annulus fibrosus of the intervertebral disc by the histochemical approach. 
ISSN: $2519-500 \mathrm{X}$

\section{Materials and methods}

The material for present study consists of 25 fully formed dead foetuses (14 male, 9 female). They were collected from Meenaz maternity hospital, Gulbarga, Karnataka, MNR medical college \& hospital, Sangareddy, Telangana India.

The dead foetuses with anomalies like spina bifida, cervical spondylosis, degenerative disc diseases and other skeletal \& vertebral deformities were excluded from the study. Normal dead foetuses were considered for this study.

All the lumbar vertebral discs are harvested during routine autopsy under anterior approach. Lumbar intervertebral discs are choose because of bigger and convenient than other region. After dissection Length and Breadth of inter vertebral discs were measured with the standard sliding calipers.

All the slices were fixed in buffered $10 \%$ formaldehyde for 24 hours and subsequently decalcified depending on the calcification of the osseous matrix of the vertebral bone. The decalcified disc slices were then embedded into paraffin as routinely performed. From the resulting blocks, paraffin sections were cut and placed on salinized glass slides for routine staining using standard histochemical protocols. The following staining methods are used

i. Haematoxylin and eosin to identify cells and fibres.

ii. Vangieson method to identify collagen fibers.

A histomorphological distinction between anular and nuclear disc tissue was performed by use of light microscopic criteria particularly under polarized light, allowing the evaluation of the organization of the collagen network.

\section{Result \& observations}

Morphological observation: The length and breadth of intervertebral disc were calculated by standard sliding callipers.

Table 1. Mean and SD of intervertebral disc in male \& female

\begin{tabular}{|l|l|l|l|l|}
\hline \multirow{2}{*}{ Sex } & \multicolumn{3}{|l|}{$\begin{array}{l}\text { Average length in } \\
\text { mm }\end{array}$} & $\begin{array}{l}\text { Average breadth in } \\
\text { mm }\end{array}$ \\
\cline { 2 - 5 } & mean & SD & Mean & SD \\
\hline Male & 11.21 & 1.01 & 18.9 & 0.85 \\
\hline Female & 11.27 & 1.05 & 18.54 & 0.78 \\
\hline
\end{tabular}

\section{Histological observations}

For descriptive purpose, the disc was analyzed in 2 parts -anulus fibrosus and nucleus pulposus. The collagen fibers in anulus are circularly, concentrically arranged and centrally placed nucleus pulposus shows multi nucleated degenerated notochordal cells seen in the form of mucoid material. 
Table 2. Histological observations of intervertebral disc

\begin{tabular}{|l|l|l|l|}
\hline \multirow{2}{*}{$\begin{array}{l}\text { Staining } \\
\text { Method }\end{array}$} & \multicolumn{2}{|l|}{ Anulus fibrosus } & Nucleus Pulposus \\
\cline { 2 - 4 } $\begin{array}{l}\text { Haematoxylin } \\
\text { \& Eosin }\end{array}$ & $\begin{array}{l}\text { Seen in lacunae } \\
\text { more in number } \\
\text { then fibers }\end{array}$ & $\begin{array}{l}\text { Circularly \& } \\
\text { Concentrically } \\
\text { arranged }\end{array}$ & $\begin{array}{l}\text { Degenerated multi } \\
\text { nucleated notochordal } \\
\text { cells are seen in the } \\
\text { form of mucoid } \\
\text { material }\end{array}$ \\
\hline Vangieson & $\begin{array}{l}\text { Seen in lacunae } \\
\text { more in number } \\
\text { then fibers }\end{array}$ & $\begin{array}{l}\text { Circularly \& } \\
\text { Concentrically } \\
\text { arranged }\end{array}$ & $\begin{array}{l}\text { Degenerated multi } \\
\text { nucleated notochordal } \\
\text { cells are seen in the } \\
\text { form of mucoid } \\
\text { material }\end{array}$ \\
\hline
\end{tabular}

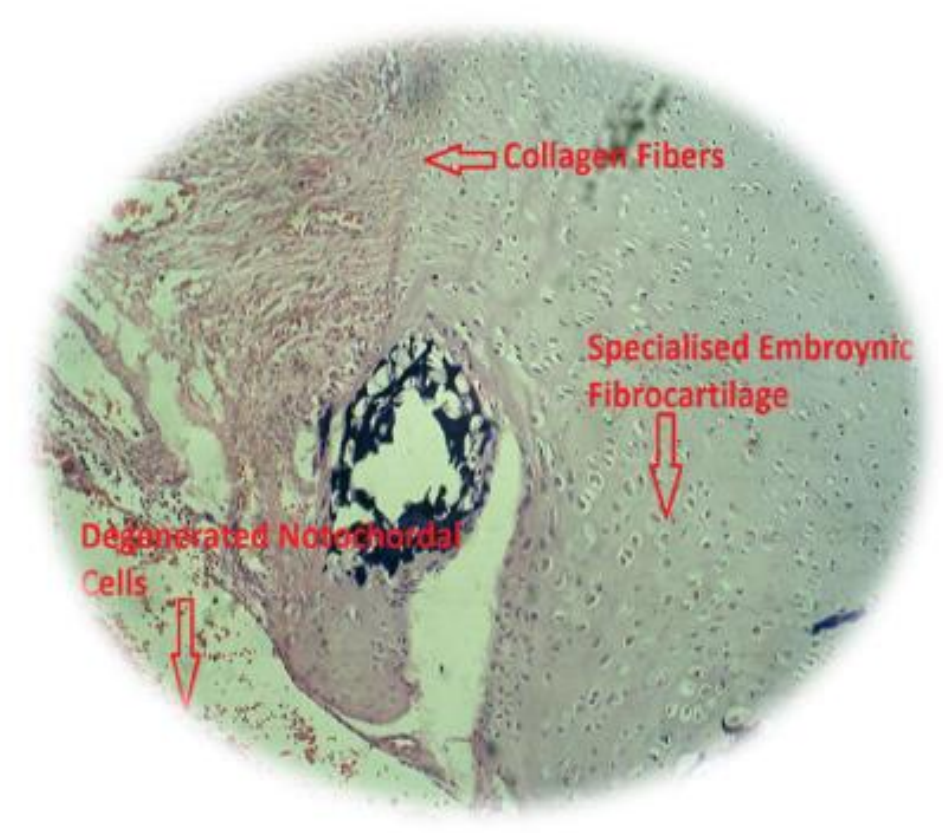

H \& E STAIN TOTAL MAGNIFICATION 10X10=100

Figure 1. Intervertebral disc showing specialized embryonic fibro cartilage 


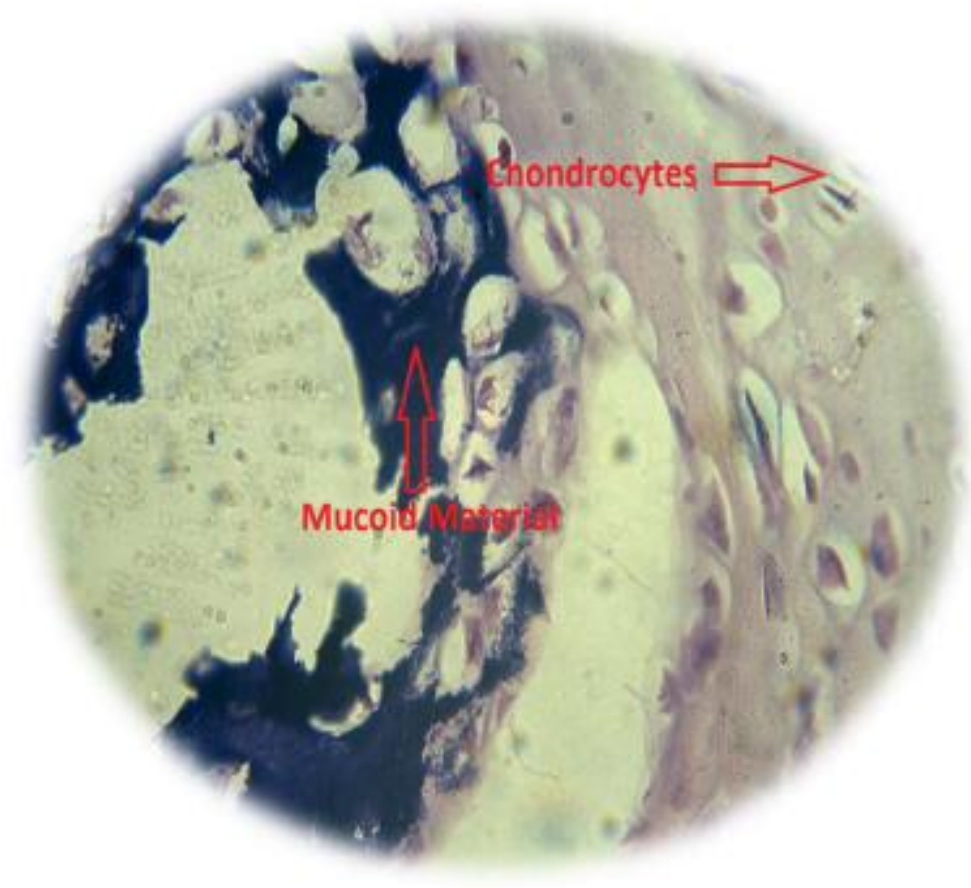

H \& E STAIN TOTAL MAGNIFICATION 40X10=400X

Figure 2. Intervertebral disc showing mucoid material

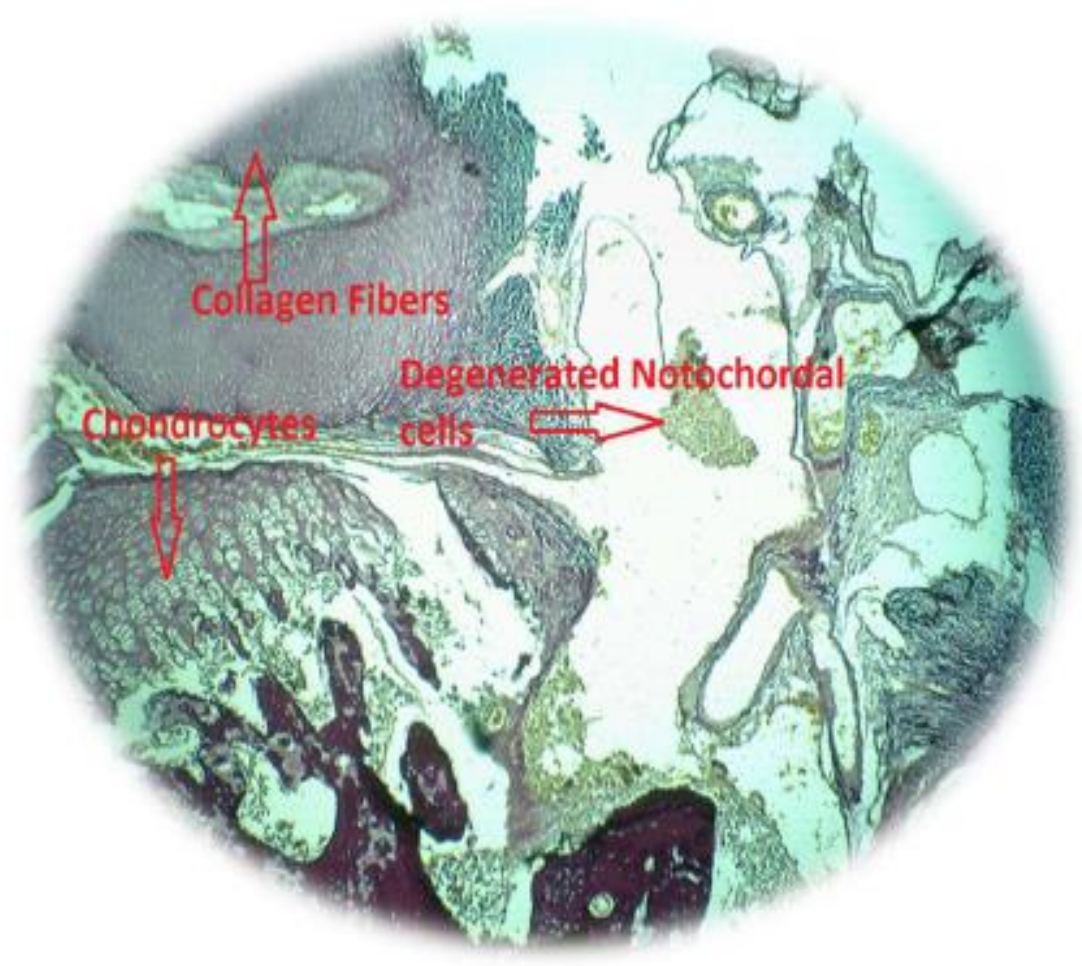

VANGIESON STAIN TOTAL MAGNIFICATION 4X10=40X

Figure 3. Intervertebral disc showing degenerated notochordal cell 


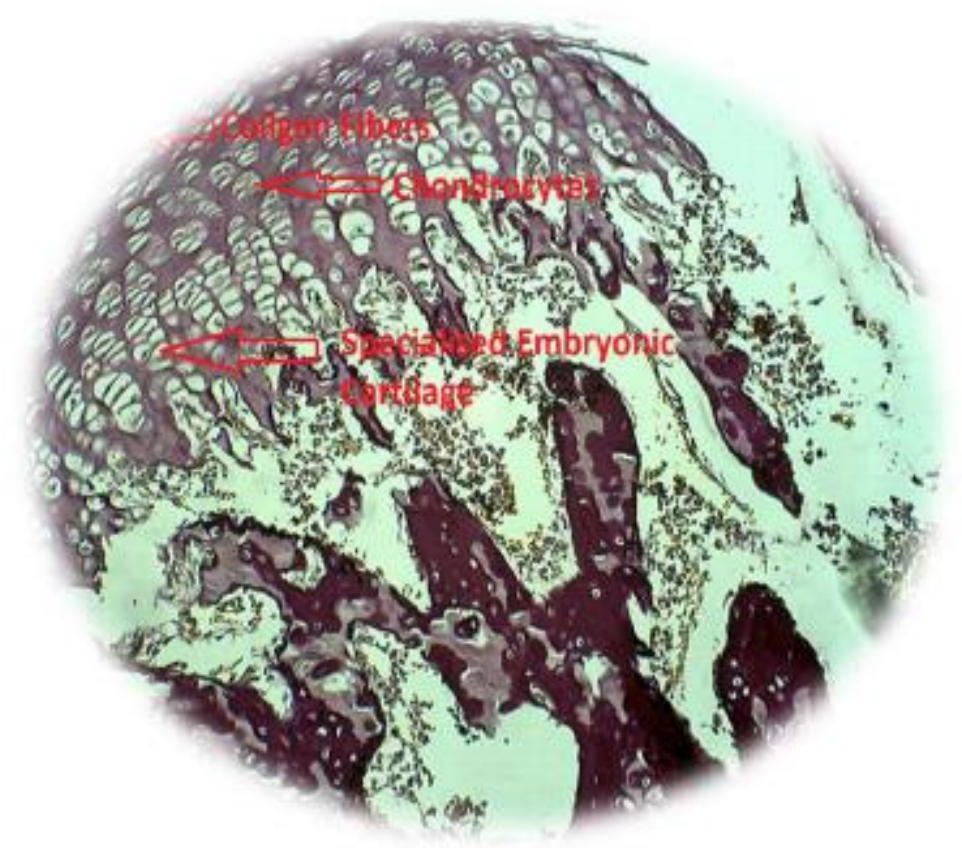

VANGIESON STAIN TOTAL MAGNIFICATION 4X10=40X

Figure 4. Intervertebral disc showing specialized embryonic fibro cartilage

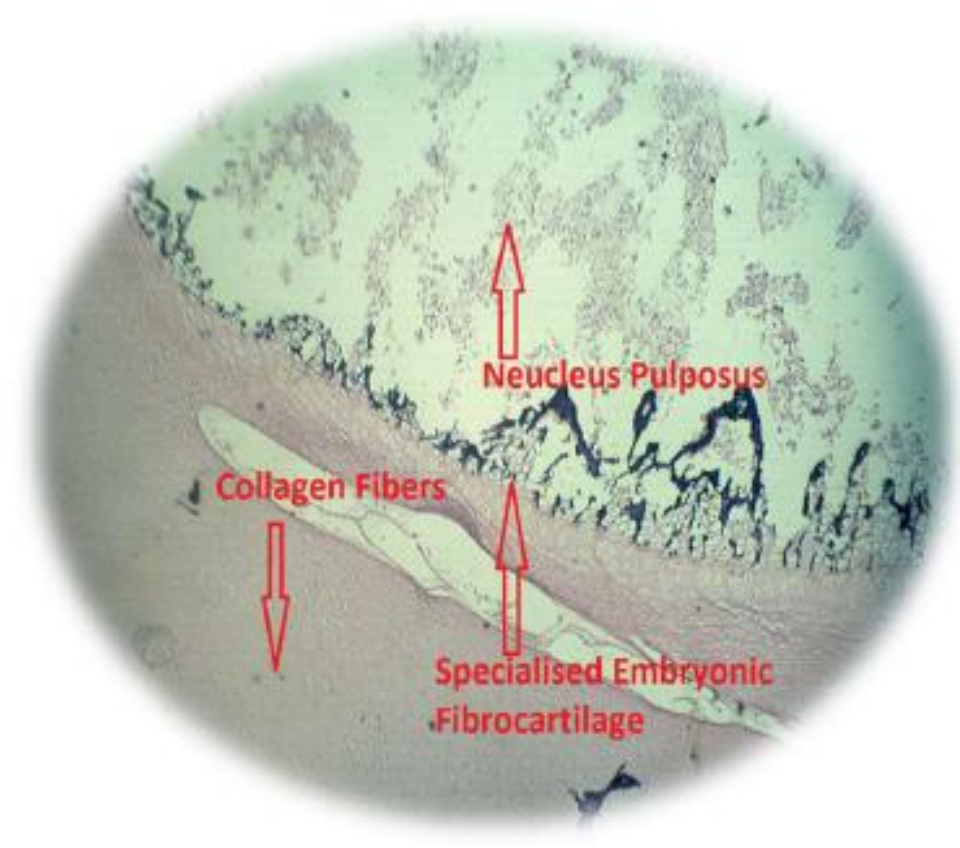

H \& E. STAIN TOTAL MAGNIFICATION 4X10=40XFig.

Figure 5. Diagrammatic representation of intervertebral disc showing anulus fibrosus and nucleus pulposus 


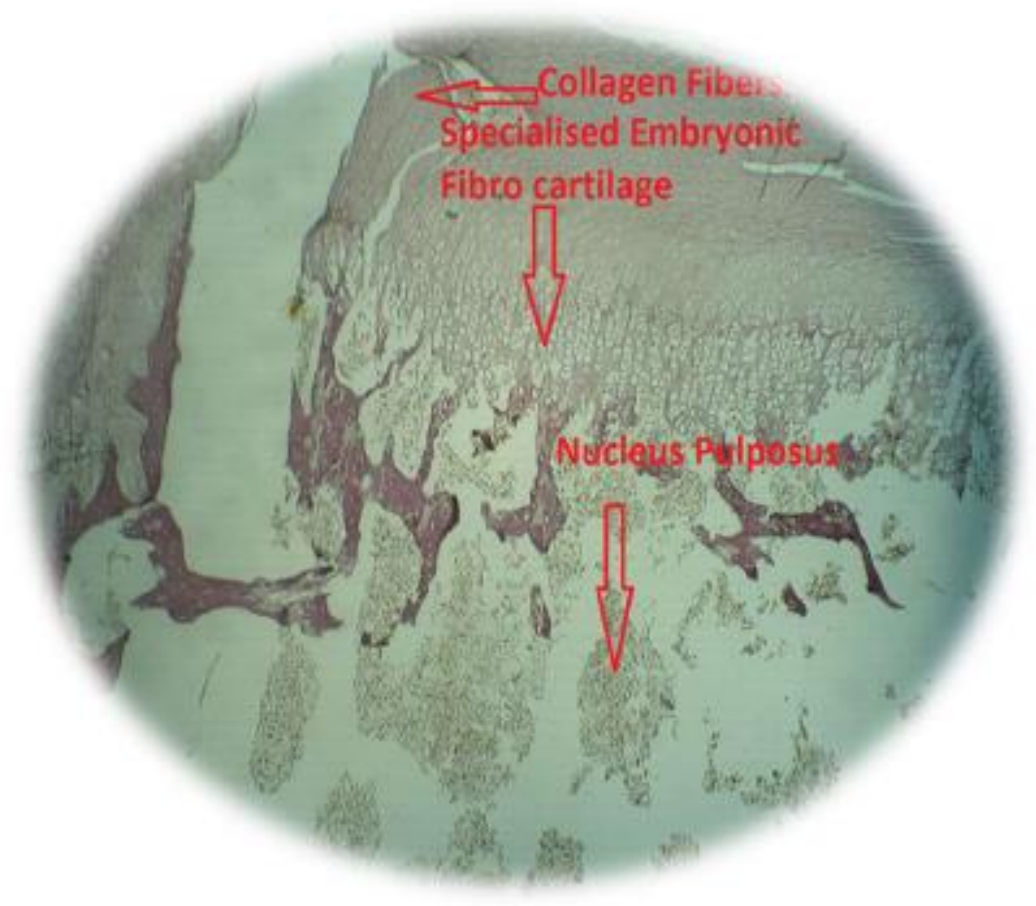

VANGIESON STAIN TOTAL MAGNIFICATION 4X10=40X

Figure 6. Diagrammatic representation of intervertebral disc showing anulus fibrosus and nucleus pulposus

\section{Discussion}

In prenatal development, the anulus fibrosus has collagen fibers which are circularly arranged and centrally placed nucleus pulposus show degenerated notochordal cells .

The intervertebral discs are subject to continuous and progressive changes throughout life so marked that it is difficult to determine what is normal and what is pathologic. (6)

Annular changes are characterized by a gradual loss of fine fibrous connective tissue meshwork and its replacement by increasingly hyalinized collagen fibers, the occurrence of fissures beginning in the third decade, cellular proliferation and enhanced cell death in the fourth decade, and finally the invasion of blood vessels along tears and clefts. In the nucleus pulposus of infants, residues of notochordal cell aggregates are replaced by proliferating chondrocytes, beginning in the second life decade. This is followed by the occurrence of tissue clefts, beginning in the fourth decade, and the progressive replacement of the nucleus by fibrous tissue from the fifth decade onward. (7).

In the morphological observations the average length of disc in males is 11.21 and $\mathrm{SD}$ is $1.01 \mathrm{~mm}$ but in females average length is 11.27 and SD is 1.05. The values showing length of the disc is minutely higher in males than females (Table 1).

The average breadth of disc in males is $18.9 \mathrm{~mm}$ and SD is 0.85 and in female average breadth is 18.54 and SD is 0.78 . These values showing breadth of the disc is slightly higher in males than females (Table 1).

In the histological observation of present study, anulus fibrosus shows circularly, concentrically arranged collagen fibers on peripheral part and centrally placed nucleus pulposus shows multi nucleated degenerated notochordal cells seen in the form of mucoid material (figure $1-6)$. 


\section{Conclusion}

It is shown by previous authors that the intervertebral disc development starts by $4^{\text {th }}$ week of intrauterine life as Mesenchymal condensation. By $10^{\text {th }}$ week, this Mesenchymal condensation differentiates in to anulus and nucleus pulposus.

The present extensive study by different special staining techniques on full term human intervertebral discs show the definite circular, concentrically arranged collagen fibers in anulus fibrosus and chondrocytes and degenerated notochordal cells in nucleus pulposus. Notochordal cells disappear after birth in the first decade of life, followed by gradual replacement of mucoid material by fibro cartilage.

\section{References}

[1]. Antoniou J, Goudsouzian NM, Heathfield TF, et al. The human lumbar endplate: Evide nce of changes in biosynthesis and denaturation of the extracellular matrix with growth, maturation, aging, and degeneration. Spine 1996; 21:1153-61.

[2]. Buckwalter JA. Spine update: Aging and degeneration of the human intervertebral disc. Spine 1995; 20:1307-14.

[3]. Coventry MB, Ghormley RK, Kernohan JW. The intervertebral disc: Its microscopic anatomy and pathology: Part II. Changes in the intervertebral disc concomitant with age. J Bone Joint Surg [Am] 1945; 27:233-47.

[4]. Coventry MB, Ghormley RK, Kernohan JW. The intervertebral disc: its microscopic anatomy and pathology: part I. anatomy, development and pathology. J Bone Joint Surg [Am] $1945 ; 27: 105-12,1945 ; 27: 460-74$.

[5]. Langman's Medical Embryology 9th edition - T. Sadler (2003)

[6]. Moore, Keith L.; Dalley, Arthur F. Clinically Oriented Anatomy, 5th Edition

[7]. Saunders JB, Inman VT. Pathology of the inter vertebral disk. Arch Surg 1940; 40: 389-416. 